\title{
The Neuroscience Community Has a Role in Environmental Conservation
}

\author{
Joyce Keifer ${ }^{1}$ and Cliff H. Summers ${ }^{1,2,3}$
}

https://doi.org/10.1523/ENEURO.0454-20.2021

${ }^{1}$ Neuroscience Group, Basic Biomedical Sciences, Sanford School of Medicine, University of South Dakota, Vermillion, SD 57069, ${ }^{2}$ Department of Biology, University of South Dakota, Vermillion, SD 57069, and ${ }^{3}$ Veterans Affairs Research Service, Sioux Falls VA Health Care System, Sioux Falls, SD 57105

\begin{abstract}
We previously argued that the neuroscience community has a role in environmental conservation because protection of biodiversity and the specialized behavioral adaptions of animals is essential to understanding brain structure and function. Preserving biodiversity and the natural world is also linked to human mental health and broadens our insight on the origins of psychiatric disorders like stress, anxiety, and depression. The study of neuroscience has become a global scientific pursuit that involves thousands of researchers and has an economic impact in the billions of dollars. As a group of biomedical research scientists, neuroscientists have the knowledge base and public credibility to convincingly promote sustainable environmental actions and policies. Here, we outline several key areas in which we as a neuroscience academic community can participate to preserve a rich global biodiversity and confront the environmental crises that lie before us.
\end{abstract}

Key words: biodiversity; comparative neuroscience; conservation; human health; neuroscience policy; sustainability

\section{Significance Statement}

Biodiversity and the global environment are currently undergoing unprecedented threats stemming from climate change and other sources of environmental stress that are rapidly leading toward widespread habitat loss and species extinction. These events endanger not only plant and animal species but human health and well-being. Environmental conservation limits habitat degradation that leads to disease from pollution, brain injury through neurotoxicity, and mental illness. Therefore, the neuroscience community has a direct stake in working for the protection and preservation of a rich global environmental biodiversity. By promoting sustainable actions, policies, and approaches to biomedical research, neuroscientists can and should have a leadership role in developing strategies that will benefit the environment and human health.

Received October 27, 2020; accepted January 20, 2021; First published February 25, 2021.

The authors declare no competing financial interests.

Author contributions: J.K. and C.H.S. wrote the paper.

This work was supported by the Neuroscience Medical Research Fund (University of South Dakota; J.K.) and the National Institutes of Health Grant R15MH104485 (to C.H.S.).

Correspondence should be addressed to Joyce Keifer at jkeifer@usd.edu or Cliff H. Summers at cliff@usd.edu.

https://doi.org/10.1523/ENEURO.0454-20.2021

Copyright (c) 2021 Keifer and Summers

This is an open-access article distributed under the terms of the Creative Commons Attribution 4.0 International license, which permits unrestricted use, distribution and reproduction in any medium provided that the original work is properly attributed.

\section{Introduction}

In a recent startling report released by the Intergovernmental Science-Policy Platform on Biodiversity and Ecosystem Services (IPBES; May, 2019; https:// www.ipbes.net/), it was estimated that at least 1 million plant and animal species are threatened by global extinction. The main catalysts of this calamitous situation are loss/degradation of habitat in land and sea, unsustainable exploitation of animals and plants, climate change resulting from increased greenhouse gas emissions, pollution, and invasive species. Many scientists believe that in this "Anthropocene epoch," humanity is approaching the sixth mass extinction in the history of Earth, the last one being 
$\sim 65$ million years ago (Barnosky et al., 2011; Ceballos et al., 2017). The IPBES study concluded that the loss of biodiversity globally is not only an environmental issue, but also an economic, social, and moral one.

In an earlier paper (Keifer and Summers, 2016), we argued that it was important for the neuroscience community to play a significant role in environmental conservation. This is because conservation efforts preserve the unique habitats that drive the emergence of specialized behavioral adaptations and their underlying neural circuitry across diverse species. Scientific investigation into the substrates of brain function and behavior has benefitted immeasurably from comparative studies of the anatomy and physiology of brains from different species (Bingman, 1992; Manger, 2011; Striedter et al., 2014; Enard, 2016; Keifer and Summers, 2016; van den Heuvel et al., 2016). Further, many of the tools currently in use for neuroscience research have been developed from a diversity of organisms, such as clinically-useful toxins/venoms (e.g., to treat cancer or channelopathies), use of bacterial light-sensitive ion channels for optogenetics, fluorescent proteins such as GFP, and CRISPR gene editing (Fenno et al., 2011; Kelsh et al., 2011; Schendel et al., 2019). A comparative approach helps neuroscience researchers identify conserved features of neural systems across animal groups that reveal fundamental genetic and physiological principals of brain structure and function. Moreover, preservation of biodiversity and the natural environment can be linked to human feelings of well-being and mental health (Bratman et al., 2015, 2019; Cabrera et al., 2016). Recognition of the interdependence of humans and nature (Comberti et al., 2015) broadens our insight into the origins of psychiatric disorders such as stress, anxiety and depression (Carr and Summers, 2002; Blanchard et al., 2013; Bratman et al., 2015). Ultimately, examining human health in the broader context of the environment translates to a deeper understanding of brain function and the etiology and treatment of human psychiatric disease.

In the face of rapidly growing environmental crises, the neuroscience community can take a leadership role in protecting and preserving a rich global environmental biodiversity. The Society for Neuroscience (SFN), the flagship scientific society for neuroscientists, has $>37,000$ members worldwide and annual expenditures of over $\$ 30$ million. Moreover, neuroscience research is allocated $\sim \$ 7$ billion from the National Institutes of Health $(\mathrm{NIH})$ each year in the United States alone. In addition to its economic impact, as a group of biomedical research scientists, we have the knowledge base and public credibility to convincingly promote sustainable environmental actions and policies. Neuroscientists also have a direct stake in preserving biodiversity both from a brain research perspective and as advocates for mental health. In this article, we outline several key areas in which we as individual scientists or as an academic community can participate to promote conservation and associated goals through modified approaches to the neuroscience research endeavor in concert with awareness of the global environment.

\section{What We Can Do as a Neuroscience Community}

\section{Leverage research funding to promote sustainable environmental impacts by corporations}

Research funding, particularly in the form of grants, used to purchase equipment and supplies by institutions and their biomedical research laboratories can be a significant force for leveraging corporations to operate in environmentally conscientious ways. Approximately $\$ 80$ billion is spent annually on basic research in the United States. How and where those funds are spent has the attention of corporate CEOs, local governments, and lawmakers. Consumer purchasing shifts the ways corporations produce and distribute goods. One example is the rapid rise in organic food production that has increased widely in recent years because of demand for healthier products by consumers. Similarly, selective purchasing from manufacturers of environmentally responsible goods and services by universities and individual research labs will drive economic markets toward positive change. To this aim, the University of California System adopted a detailed Policy on Sustainable Practices in 2019 (https://www. ucop.edu/sustainability/policy-areas/index.html). This policy describes system-wide goals and guidelines in nine areas including clean building design and sustainable transportation, foodservices, energy, and water usage. Sustainable procurement was highlighted because purchasing decisions that reduce negative impacts on the environment should have priority. Many other universities have followed suit and have established large sustainability initiatives. Smaller sustainability programs promoted by student groups have also begun to make an impact. Such programs in North America are tracked and rated (the green score) by the Association for the Advancement of Sustainability in Higher Education (https://www.aashe.org/). These efforts will have an important impact on reducing potentially harmful consequences of biomedical research and other campus activities on the environment. Individual neuroscience laboratories can also take initiatives to purchase environmentally friendly products where possible. For example, academic consumers can inform sales representatives that they are interested in purchasing goods made from and shipped using recyclable and biodegradable materials. Moreover, researchers can request that items be packaged and shipped together to use less packing material and consumption of fuel to deliver them. This "sustainable procurement and consumption" approach by universities and neuroscience research labs will have the overall effect of diminishing the environmental impact of doing biomedical research. While these initiatives are a good start to increasing sustainability, the challenge is in making these alternatives systemic to the marketplace. If efforts to conserve resources are time consuming and laborious, they will fail. A case in point is, again, organic goods. Some years ago, such products were of limited availability and difficult to find. But increased public awareness of the health and environmental benefits combined with responsive farmers and manufacturers stimulated substantial growth of this industry (Mie et al., 2017; Demirtas, 2019). Today, organic products 
and foods are now abundant and acquired easily in most stores (although the growth of this movement was aided by an act of Congress to establish national standards). If the past is instructive, then the persistence of the academic consumer and their purchasing power will drive industrious suppliers to respond with more environmentally friendly products and services. Making these sustainable practices a systemically marketplace-driven reality would be facilitated by the participation of large scientific societies such as the SFN and governmental agencies like the $\mathrm{NIH}$ that have important roles in supporting biomedical research.

\section{Decrease overconsumption by neuroscience laboratories}

The impact of overconsumption of laboratory animals, supplies, services, water and energy and the subsequent generation of biomedical waste by the medical field contributes to a severe impact on the environment (Manzoor and Sharma, 2019). These activities combine to result in global climate change, habitat destruction, toxic pollution from hazardous materials, and decline in species and biodiversity. Neuroscience research contributes to a relatively small percentage of the waste generated compared with hospitals and other health care facilities, but it is hardly inconsequential. Neuroscience researchers are increasingly concerned about the impact of their labs on the local community and are looking for ways to make their work more ecologically sustainable. Along with the sustainability initiatives described above, changes in standard lab practices can lead to "green labs" (Webb, 2016; Gross, 2018; Zimmer, 2018; Zak et al., 2020). Many lab procedures are performed from entrenched practices and habit. Examples include constantly changing pipette tips or unnecessarily using new plastic PCR tubes. Cutting down on consumables, especially disposable single-use plastics, not only saves the lab money but reduces the amount of waste that goes into landfills. Simple ideas like lowering the set temperature of ultra-low freezers from $-80^{\circ} \mathrm{C}$ to $-70^{\circ} \mathrm{C}$ significantly reduces the energy used without being detrimental to samples. Closing chemical fume hoods reduces energy usage and costs. This has led to "Shut the Sash" initiatives at many universities. Powering down computers and other equipment not in use would also contribute to energy savings. Since individual researchers do not directly pay the energy usage bills of their institutions, one idea is to post energy consumption data outside of labs. This might encourage greater frugality and friendly competition among labs to conserve, especially if there was a system of reward. Along these lines, standard autoclaves use $\sim 50$ gallons of water per minute when in use. Far more efficient instruments (e.g., Water-Mizer) are available that reduce water usage by half and should be considered when autoclaves need replacement. There are a number of online resources for researchers to consult to help make their labs greener and reduce their environmental impact (Webb, 2016).

\section{Reduce travel to neuroscience conferences}

Global aviation contributes $2.4 \%$ of all carbon dioxide $\left(\mathrm{CO}_{2}\right)$ emissions from fossil fuels. This amount would have ranked sixth compared with nations and was the largest source of $\mathrm{CO}_{2}$ from energy producers in 2015 (Graver et al., 2020). Accounting for contrails and other greenhouse gas emissions from air travel pushes that figure higher. The environmental impact of travel is becoming an increasing concern among the scientific research community and there is an expanding willingness to explore new options (Pulizzi, 2019; Geitmann, 2020; Haage, 2020). One possibility is for departments to host more seminar speakers from nearby institutions. This option has the added benefit of potentially increasing collaborations. Currently, the arrival of the COVID-19 pandemic and ensuing cancellations of meetings and reluctance to travel on the part of attendees, particularly by plane, has resulted in the wide use of alternatives to in-person attendance at conferences and other speaking events. Neuroscientists should push large scientific societies like the SFN and those in Europe represented by the Federation of European Neuroscience Societies (FENS) toward providing remote access to their annual meetings. New platforms increase the available options for videoconferencing through Internet services. Notably, the FENS Forum 2020 meeting was held entirely online and was accessible worldwide. Smaller meetings, workshops, and departmental seminars could be augmented or hosted by resources such as Zoom (https://www.zoom.us/), which is now commonly used in academics because of the pandemic. This would allow departments to reduce the costs of seminars and host more speakers. The NIH has also experimented with holding Internet and video assisted study section meetings. The effectiveness of this approach, however, is somewhat controversial and is still being evaluated. Although virtual seminars are not likely to completely replace scientific meetings, use of these resources can give neuroscientists a choice to limit travel in the future and significantly reduce the carbon footprint of individual researchers for the long term (Geitmann, 2020). Another significant point with regard to remote meeting access is that it will substantially enhance the equity and inclusion of speakers and attendees. Scientists who have difficulty or are reluctant to travel because of child care, expense, disability, scheduling, or a variety of other reasons, could more easily participate in study sections, give seminars, and attend meetings if they are held online. Remote access would also be global, opening the door to investigators in economically challenged countries or remote locations. Implementation and expanded use of remote viewing could be a major benefit to neuroscience research overall. More detailed recommendations for enhancing sustainable travel behavior can be found elsewhere (Haage, 2020). One benefit of reducing time-consuming long-haul travel is that the time spent away from labs and students will decline, thereby increasing overall productivity and the quality of home life for individuals.

\section{Advance public policies for lawmakers that promote environmental conservation and human health}

Strategies that contribute significantly to sustainability efforts and changes in environmental policy that benefit the environment and human health should be advanced by 
neuroscience societies and organizations. Environmental degradation impacts human health in numerous ways including malnutrition and injury as a result of natural disasters such as drought and flooding that have intensified, spread of vector-borne diseases because of global warming, and toxicity leading to chronic diseases from air and water pollution (Myers et al., 2013; Rossati, 2017; Morens and Fauci, 2020). Far less attention is given to mental health and well-being (Cabrera et al., 2016; Bratman et al., 2019), problems that are just as pervasive and personally devastating. Moreover, the cultural worldviews of indigenous peoples and their place in nature factors into loss of feelings of self-worth, stability and wellness when local ecosystems decline. Scientific neuroscience societies like the SFN can significantly impact policy development to promote a healthier environment for wildlife and humans. Currently, most of the advocacy efforts of the SFN, FENS, and other groups are focused on promoting the advancement of neuroscience and research funding targeting brain injury and disease. In our view, however, this is a missed opportunity. Neuroscience societies should be more actively engaged in supporting environmental justice, preservation, and sustainability to create a safer, less toxic, less stressful world. Importantly, positive change in resolving these concerns will result in a reduction of neurologic and mental health burdens. Along these lines, environmental sustainability adds economic value and jobs related to the changes required from current practice such that economic well-being associated with these efforts has positive effects on mental health. These economic changes may be simple, such as converting conventionally plowed fields to no-till farming. This results in reduction of legacy $\mathrm{CO}_{2}$ concentration in the atmosphere, improves sustainability, regenerates soil quality, and provides greater profit for farmers while reducing the environmental load of toxic chemicals (Rainbow and Derpsch, 2011; Osei et al., 2012). Better economic outcomes, especially in combination with environmental improvement, surely promotes improved mental health. Further, there could be targeted efforts to address specific opportunities or concerns raised by neuroscience research to drive political policy changes that improve the environment and the human condition. Issues, for example, like the effects of environmental neurotoxins on brain development (such as the lead water crisis that occurred in Flint, MI, in 2014 and is ongoing; Ruchart et al., 2019), or sonar interference by military operations on animal navigation (naval sonar interference resulting mass strandings of whales; Tyack et al., 2011; Goldbogen et al., 2013; Morell, 2015), should be addressed using scientific data and potential solutions offered by experts. These groups could also strengthen their effectiveness by partnering with other scientific (American Association for the Advancement of Science, AAAS) and worldwide organizations (the Intergovernmental Panel on Climate Change of the UN) to enhance public awareness and advance informed positions on significant global issues such as climate change. Ultimately, the advocacy of scientific societies is driven by the membership they represent. Members who are also scientific experts create an important additional political force for influencing legislators that there is significant scientific consensus for new laws related to climate change, environmental and wildlife conservation, and reduction of toxic pollutants, as well as the health and well-being issues that environmental problems promote.

\section{Outlook for the future}

We have unexpectedly learned from the COVID-19 pandemic that some of the negative impacts of human activities on Earth can be reversible. Satellite imaging revealed that during the time of global quarantine starting in early 2020, carbon emissions dramatically declined and the atmosphere became clearer and cleaner worldwide, particularly over urban areas (Le Quere et al., 2020; Earth Observing Dashboard, https://www.eodashboard.org/). Anecdotal reports indicate that wildlife activity near towns and cities normally reduced during the day to avoid humans has increased and taken on more natural patterns (Rutz et al., 2020). Although these positive changes must be sustained to have a lasting global impact on the environment, the current COVID-19 crisis is instructive. It offers a temporary worldwide laboratory to examine the effects of human activity on our planet that points research, and some inventive thinking, toward significant steps that can be taken to reduce our impact. While these positive changes give us hope, they do not suggest that the severe damage done to the Earth's environment can be rectified quickly. Global climate change is promoted by feedback loops between the atmosphere and biomass that further support increased $\mathrm{CO}_{2}$ levels and temperature (van Nes et al., 2015; Curran and Curran, 2016; Williams et al., 2019). These complex interactions are just beginning to be understood and it is thought they can become self-sustaining if human activity is not changed. It is possible that we are near, or have already passed, the threshold for this carbon-cycle feedback system in forcing climate change. The time to act is now. Reversing the environmental damage caused by human populations to the Earth will require transformational economic and social change. The neuroscience research community can help lead the way for other professional scientific organizations to leverage their knowledge, authority and will to bring about significant change that addresses the global crises that confront us.

\section{References}

Barnosky AD, Matzke N, Tomiya S, Wogan GOU, Swartz B, Quental TB, Marshall C, McGuire JL, Lindsey EL, Maguire KC, Mersey B, Ferrer EA (2011) Has the earth's sixth mass extinction already arrived? Nature 471:51-57.

Bingman VP (1992) The importance of comparative studies and ecological validity for understanding hippocampal structure and cognitive function. Hippocampus 2:213-219.

Blanchard DC, Summers CH, Blanchard RJ (2013) The role of behavior in translational models for psychopathology: functionality and dysfunctional behaviors. Neurosci Biobehav Rev 37:1567-1577.

Bratman GN, Hamilton JP, Hahn KS, Daily GC, Gross JJ (2015) Nature experience reduces rumination and subgenual prefrontal cortex activation. Proc Natl Acad Sci USA 112:8567-8572.

Bratman GN, Anderson CB, Berman MG, Cochran B, de Vries S, Flanders J, Folke C, Frumkin H, Gross JJ, Hartig T, Kahn PH, Kuo 
M, Lawler JJ, Levin PS, Lindahl T, Meyer-Lindenberg A, Mitchell R, Ouyang Z, Roe J, Scarlett L, et al. (2019) Nature and mental health: an ecosystem service perspective. Sci Adv 5:eaax0903.

Cabrera LY, Tesluk J, Chakraborti M, Matthews R, Illes J (2016) Brain matters: from environmental ethics to environmental neuroethics. Environ Health 15:20.

Carr JA, Summers CH (2002) Is stress more than a disease? A comparative look at the adaptiveness of stress. Integr Comp Biol 42:505-507.

Ceballos G, Ehrlich PR, Dirzo R (2017) Biological annihilation via the ongoing sixth mass extinction signaled by vertebrate population losses and declines. Proc Natl Acad Sci USA 114:E6089-E6096.

Comberti C, Thornton TF, de Echeverria VW, Patterson T (2015) Ecosystem services or services to ecosystems? Valuing cultivation and reciprocal relationships between humans and ecosystems. Glob Environ Change 34:247-262.

Curran JC, Curran SA (2016) Indications of positive feedback in climate change due to a reduction in Northern Hemisphere biomass uptake of atmospheric carbon dioxide. Weather 71:88-91.

Demirtas B (2019) Assessment of the impacts of the consumers' awareness of organic food on consumption behavior. Food Sci Technol 39:881-888.

Enard W (2016) The molecular basis of human brain evolution. Curr Biol 26:R1109-R1117.

Fenno L, Yizhar O, Deisseroth K (2011) The development and application of optogenetics. Annu Rev Neurosci 34:389-412.

Geitmann A (2020) Travel less. Make it worthwhile. Cell 182:790793.

Goldbogen JA, Southhall BL, DeRuiter SL, Calambokidis J, Friedlaender AS, Hazen EL, Falcone EA, Schorr GS, Douglas A, Moretti DJ, Kyburg C, McKenna MF, Tyack PL (2013) Blue whales respond to simulated mid-frequency military sonar. Proc Biol Soc 280:20130657.

Graver B, Rutherford D, Zheng S (2020) $\mathrm{CO}_{2}$ emissions from commercial aviation, 2013, 2018, and 2019. Int Council Clean Transport, pp 1-36.

Gross K (2018) Green labs: how to be environmentally sustainable in biomedical research. Insight. Available at https://sites.tufts.edu/ insight/2018/10/18/green-labs-how-to-be-environmentally-sustainablein-biomedical-research/.

Haage V (2020) A survey of travel behaviour among scientists in Germany and the potential for change. Elife 9:e56765.

Keifer J, Summers CH (2016) Putting the "biology" back into "neurobiology": the strength of diversity in animal model systems for neuroscience research. Front Syst Neurosci 10:69.

Kelsh RN, Székely T, Stuart S (2011) Why should biomedical scientists care about biodiversity? Curr Biol 21:R210-R211.

Le Quere C, Jackson RB, Jones MW, Smith AJP, Abernethy S, Andrew RM, De-Gol AJ, Willis DR, Shan Y, Canadell JG, Friedlingstein P, Creutzig F, Peters GP (2020) Temporary reduction in daily $\mathrm{CO}_{2}$ emissions during COVID-19 forced confinement. Nat Clim Chang 10:647-653.

Manger PR (2011) Collectibles and collections for comparative and evolutionary neurobiological research in Africa. Ann NY Acad Sci 1225:E85-E93.

Manzoor J, Sharma M (2019) Impact of biomedical waste on environment and human health. Environ Claims J 31:311-334.

Mie A, Andersen HR, Gunnarsson S, Kahl J, Kesse-Guyot E, Rembiałkowska E, Quaglio G, Grandjean P (2017) Human health implications of organic food and organic agriculture: a comprehensive review. Environ Health 16:111.

Morell V (2015) US navy to limit sonar testing to protect whales. Science Mag. Available at http://www.sciencemag.org/news/ 2015/09/us-navy-limit-sonartesting-protect-whales.

Morens DM, Fauci AS (2020) Emerging pandemic diseases: how we got to COVID-19. Cell 182:1077-1092.

Myers SS, Gaffikin L, Golden CD, Ostfeld RS, Redford KH, Ricketts TH, Turner WR, Osofsky SA (2013) Human health impacts of ecosystem alteration. Proc Natl Acad Sci USA 110:18753-18760.

Osei E, Moriasi D, Steiner JL, Starks PJ, Saleh A (2012) Farm-level economic impact of no-till farming in the Fort Cobb Reservoir Watershed. J Soil Water Conserv 67:75-86.

Pulizzi F (2019) Scientists should explore alternatives to flying. Nat Nanotechnol 14:813.

Rainbow R, Derpsch R (2011) Advances in no-till farming technologies and soil compaction management in rainfed farming systems. In: Rainfed farming systems (Tow P, Cooper I, Partridge I, Birch C, eds). Dordrecht: Springer.

Rossati A (2017) Global warming and its health impact. Int J Occup Environ Med 8:7-20.

Ruchart PZ, Ettinger AS, Hann-Attisha M, Jones N, Davis SI, Breysse PN (2019) The Flint water crises: a coordinated public health emergency response and recovery initiative. J Public Health Manag Pract 25 [Suppl 1]:S84-S90.

Rutz C, Loretto MC, Bates AE, Davidson SC, Duarte CM, Jetz W, Johnson M, Kato A, Kays R, Mueller T, Primack RB, RopertCoudert Y, Tucker MA, Wikelski M, Cagnacci F (2020) COVID-19 lockdown allows researchers to quantify the effects of human activity on wildlife. Nat Ecol Evol 4:1156-1159.

Schendel V, Rash LD, Jenner RA, Undheim EAB (2019) The diversity of venom: the importance of behavior and venom system morphology in understanding its ecology and evolution. Toxins 11:666.

Striedter GF, Belgard TG, Chen CC, Davis FP, Finlay BL, Güntürkün O, Hale ME, Harris JA, Hecht EE, Hof PR, Hofmann HA, Holland LZ, Iwaniuk AN, Jarvis ED, Karten HJ, Katz PS, Kristan WB, Macagno ER, Mitra PP, Moroz LL, et al. (2014) NSF workshop report: discovering general principals of nervous system organization by comparing brain maps across species. Brain Behav Evol 83:1-8.

Tyack PL, Zimmer WMX, Moretti D, Southall BL, Claridge DE, Durban JW, Clark CW, D'Amico A, DiMarzio N, Jarvis S, McCarthy E, Morrissey R, Ward J, Boyd IL (2011) Beaked whales respond to simulated and actual navy sonar. PLoS One 6:e17009.

Van den Heuvel MP, Bullmore ET, Sporns O (2016) Comparative connectomics. Trends Cogn Sci 20:345-361.

Van Nes EH, Scheffer M, Brovkin V, Lenton TM, Ye H, Deyle E, Sugihara G (2015) Causal feedbacks in climate change. Nature Clim Change 5:445-448.

Webb S (2016) Going greener. BioTechniques 60:224-228.

Williams RG, Katavouta A, Goodwin P (2019) Carbon-cycle feedbacks operating in the climate system. Curr Clim Change Rep 5:282-295.

Zak JD, Wallace J, Murthy VN (2020) How neuroscience labs can limit their environmental impact. Nat Rev Neurosci 21:347-348.

Zimmer K (2018) Life scientists cut down on plastic waste. Scientist. Available at https://www.the-scientist.com/careers/life-scientistscut-down-on-plastic-waste-64547. 